\title{
Clinical study on the variability in the distance between apical constriction determined by an apex locator and the radiographic apex
}

\author{
Fatou Leye Benoist, ${ }^{1}$ Mouhamed Sarr, ${ }^{1}$ Khaly Bane, ${ }^{1}$ Mamadou Lamine Ndiaye, ${ }^{2}$ \\ Diouma Ndiaye, ${ }^{1}$ Ghita Tlemsani Benhattal, ${ }^{1}$ Babacar Faye' \\ 'Department of Conservative Dentistry and Endodontics, University Cheikh Anta Diop of Dakar, Dakar, Senegal \\ ${ }^{2}$ Department of Rodiology Dento-maxillofacial, University Cheikh Anta Diop of Dakar, Dakar, Senegal
}

Objective: To determine the variability in the distance between apical constriction determined by an apex locator and the radiographic apex on digital radiographs in a Moroccan population.

Methods: Once the apex locator indicated the position of the apical constriction marked by 0.5 , an existing lime X-ray was taken and measurements were made using the Kodak Dental Imaging Software 6.10.8.3.

Results: The average distance between the tip of the instrument and the radiographic apex (DTIRA) was $0.792 \mathrm{~mm}+0.61$. The position of the apical constriction at $0.5 \mathrm{~mm}$ of the radiographic apex is in only $21 \%$ of selected teeth. Ninety eight out of 100 teeth had a DRLAAR of $<2 \mathrm{~mm}$. Considering these 98 teeth, $40.8 \%$ of them had a DTIRA in the range of $0-0.5 \mathrm{~mm}, 38.8 \%$ in the range of $0.5-1 \mathrm{~mm}$, and $20.4 \%$ had DTIRA of $>1 \mathrm{~mm}$.

Conclusion: There is a great variability in the distance between the apical constriction determined by an apex locator and the radiographic apex on digital radiographs in this population. Indeed, the subtraction of $0.5 \mathrm{~mm}$ from the latter, as recommended by several authors, is in only $21 \%$ of selected teeth.

Keywords: Dental radiography; root canal preparation; tooth apex.

$\mathrm{D}$ uring root canal treatment, canal preparation and obturation should stop at the cementodentinal junction. However, the stop location is detectable only histologically. ${ }^{[1]}$ Determining the endodontic apical stop is a crucial step in canal treatment, and the success or failure of the treatment depends on correctly identifying the stop location. ${ }^{[2]}$

Several methods for determining the length are now available, and the best known approach was reported by Kuttler. $^{[1]}$ The method recommends a canal preparation at
$0.5 \mathrm{~mm}$ from the radiographic apex, and the apical constriction is, on average, located at this distance from the anatomical apex. However, the anatomy of this area is by definition different for each individual, and stopping the preparation to an estimated level does not allow for the evaluation of the remaining channel length.

For a long time, X-rays remained essential for determining endodontic apical stops. However, estimates obtained from X-rays are considered approximate and biased ${ }^{[3]} \mathrm{X}$-ray images alone cannot precisely determine the

Correspondence: Dr. Fatou Leye Benoist. Bp 16014 Dakar-fann, Senegal 12522 Dakar - Senegal.

Tel: 00221775247885 e-mail: fatou.leye@ucad.edu.sn

Submitted: March 19, 2018 Accepted: June 01, 2018 
canal length due to the extreme variability of apical curvatures throughout the entire surface and the accumulation of apical cementum.

Currently, there are electronic methods that provide more details on the position of endodontic apical stops. ${ }^{[4]}$

The aim of this study was to determine the variability in the distance between apical constriction determined by an apex locator and the radiographic apex on digital radiographs using the Kodak Dental Imaging Software ${ }^{\circledast}$ (Eastman Kodak Company, Rochester, NY, USA) in a Moroccan population.

\section{Materials and methods}

This is a cross-sectional descriptive study conducted at a dental center in Agadir, Morocco. A sample size of 100 was calculated with the Schwartz formula.

\section{Inclusion criteria}

The inclusion criteria of this study were as follows:

- patient age of 16-65 years

- consent to participate in the study

The chosen tooth had to meet the following criteria:

- normal root morphology on X-ray

- no root resorption or canal calcification

- monoradicular with vital pulp

The following exclusion criteria were used in this study:

- non-consent to participate in the study

- presence of significant root resorption

- canal calcification

- radicular curvature preventing exploration of the apical third.

All patients signed informed consent after receiving detailed explanations of the course of the study. The Commission for Medical Ethics approved the study, and the principles of the Declaration of Helsinki were respected.

\section{Protocol}

Anesthesia was induced around the affected tooth after clinical examination. A rubber dam isolation was performed, and the access cavity was prepared before the canal was flushed with a $2.5 \%$ sodium hypochlorite solution. An apex locator Morita Root ZX (J Morita, Tokyo, Japan) was used. The apex locator's labial electrode was placed at the level of the tooth to be treated in the opposite sector, and any contact with metal (cast crown, amalgam, metallic PAP, etc.) was avoided. A file with a diameter of 10,15 , or
20 (depending on the canal width) was connected to the instrumental electrode and inserted into the root canal. The instrument's screen indicated the progress with blue lines at the beginning and then green lines, which were accompanied by a long beep at the approach of the apex corresponding to the interval $[-1 \mathrm{~mm}$; "APEX"]. Once the apex locator indicated the position of the apical constriction marked by 0.5 , the file was held in this position, and the stop was adjusted to an occlusal mark. The electrode was disconnected from the pin and removed from the mouth along with the lip electrode. An X-ray was taken using an Endo Ray angulator (Rinn/Dentsply, Maillefer, Tulsa, OK, USA), which consists of a digital sensor and the X-ray source. The image was archived in a computer before analysis.

\section{Judgment criterion}

The Kodak Dental Imaging Software 6.10.8.3 was used to measure the distance between the instrument tip and the radiographic apex (Fig. 1). Measurements were made by clicking on the Measurement tool at the top left of the Kodak Dental Imaging Software 6.10.8.3 toolbar. The cursor was then placed at the end of the pin visible on the $\mathrm{X}$-ray, which is connected to the radiographic apex. The measurement was displayed at the middle bottom of the screen. All measurements were made on a $1 / 1$ scale.

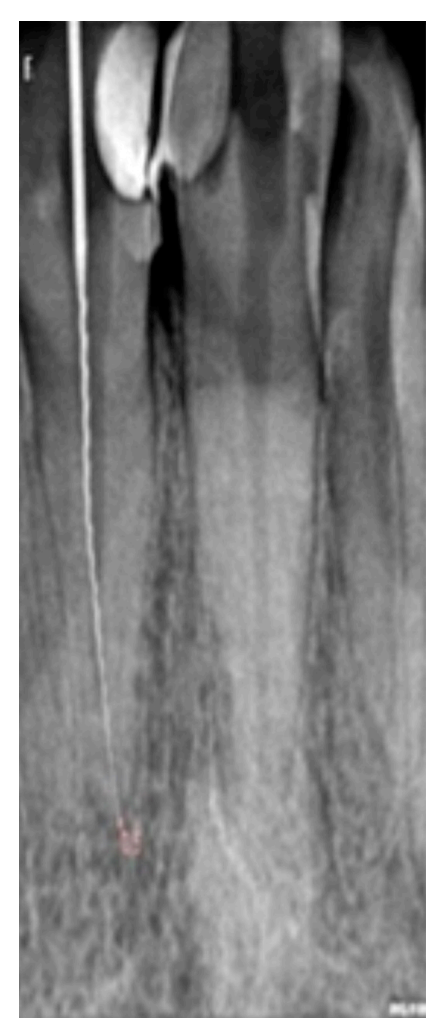

Fig. 1. Existing lime $X$-ray indicating the software measurement method. 


\section{Statistical analysis}

Data were analyzed using the IBM Statistical Package for Social Sciences (SPSS) software (version 11.0 for Windows, SPSS Inc., Chicago, IL, USA), and the statistical significance level was set at $\mathrm{p} \leq 0.05$. Qualitative variables were described by their number and frequency, and quantitative variables were described by their mean and standard deviation.

The measurement reliability was tested by the intraclass correlation coefficient (ICC) calculation to verify the consistency of the two assessments performed with the same X-ray image. The ICC was calculated using the absolute approval and the basis of definition is equal to 0.872 with a confidence interval of $0.691-0.950(\mathrm{p}=0.001)$.

\section{Results}

One hundred teeth were obtained from 66 patients $(45$ females and 21 males) in this study. Data indicated that $68.18 \%$ of the participants were female, and their average age was $35.35 \pm 9.89$ years. The average age of the male subjects was $35.28 \pm 12.64$ years. The male:female ratio was 0.466 . There was no significant difference between the number of males and females $(\mathrm{p}=0.946)$ (Table 1$)$. The maxillary anterior teeth were the most representative in this study, accounting for $87.8 \%$ of all teeth studied. The average distance between the tip of the instrument (identified by the apex locator as the apical constriction) and the radiographic apex (DTIRA) was $0.792 \pm 0.61 \mathrm{~mm}$ (maximum: $4.4 \mathrm{~mm}$, minimum $0.0 \mathrm{~mm}$ ) (Table 2). The patients were divided into two age groups. The first group included patients aged 16-35 years and with an average DTIRA of $0.776 \pm 0.57 \mathrm{~mm}$. The second group included patients aged 36-59 years and an average DTIRA of $0.808 \pm 0.653 \mathrm{~mm}$. There was a statistically significant difference in values between these two age groups $(\mathrm{p}=0.001)$.

In this study, the average DTIRA of the maxillary teeth was $0.797+0.671 \mathrm{~mm}$ (minimum: $0 \mathrm{~mm}$, maximum: 4.4 $\mathrm{mm}$ ). The average DTIRA of the mandibular teeth was $0.775+0.374 \mathrm{~mm}$ (minimum: $0.1 \mathrm{~mm}$, maximum: 1.6 $\mathrm{mm})$. No statistically significant difference was noted $(\mathrm{p}=0.948)$.

The results of this study showed the position of the apical constriction at $0.5 \mathrm{~mm}$ of the radiographic apex in only $21 \%$ of selected teeth. Ninety eight of the 100 teeth had a DTIRA of $<2 \mathrm{~mm}$. The results showed that $40.8 \%$ of the 98 evaluated teeth had a DTIRA of $0-0.5 \mathrm{~mm}, 38.8 \%$ had a DTIRA of $0.5-1 \mathrm{~mm}$ ], and $20.4 \%$ had a DTIRA greater than $1 \mathrm{~mm}$.

\section{Discussion}

This work has several limitations. The study was performed on a sample consisting exclusively of monoradicular teeth. The molars were excluded from this work because their canal anatomy if often more complex.

Table 1. Distribution of subjects according to sex, age, and tooth location

\begin{tabular}{|c|c|c|c|c|c|c|c|c|}
\hline & & \multirow[t]{2}{*}{$\mathbf{n}$} & \multirow[t]{2}{*}{$\%$} & \multicolumn{5}{|c|}{ Age (years) } \\
\hline & & & & Mean & SD & Min & Max & $\mathbf{p}$ \\
\hline \multirow[t]{2}{*}{ Sex } & Male & 45 & 68.18 & 35.35 & 9.89 & 17 & 58 & 0.946 \\
\hline & Female & 21 & 31.81 & 35.28 & 12.64 & 16 & 59 & \\
\hline \multirow[t]{2}{*}{ Maxilla } & Incisor/canine & 72 & 72 & & & & & \\
\hline & Premolar & 4 & 4 & & & & & \\
\hline \multirow[t]{2}{*}{ Mandibula } & Incisor/canine & 10 & 10 & & & & & \\
\hline & Premolar & 14 & 14 & & & & & \\
\hline
\end{tabular}

SD: Standard deviation.

Table 2. DTIRA according to sex, age group, and tooth location

\begin{tabular}{llccccc} 
& DTIRA & Mean & SD & Min & Max & P \\
Population & & 0.792 & 0.61 & 0.0 & 4.4 & \\
Sex & Male & 0.913 & 0.609 & 0 & 3.1 & 0.441 \\
& Female & 0.742 & 0.609 & 0 & 4.4 & \\
16-35 years group & & 0.776 & 0.572 & 0 & 3.1 & 0.001 \\
36-59 years group & & 0.808 & 0.653 & 0 & 4.4 & \\
Tooth location & Maxilla & 0.797 & 0.671 & 0 & 4.4 & 0.948 \\
& Mandibula & 0.775 & 0.374 & 0.1 & 1.6 & \\
\hline
\end{tabular}

SD: standard deviation; DTIRA: distance between the tip of the instrument and the radiographic apex. 
An additional limitation is that these results were not confirmed by a histological study.

The choice of the apical stop is one of the most important decisions and is the most controversial step in endodontics treatment. The concept of confining the canal space preparation without instrumental overtaking is unanimous. Conversely, opinions diverge on the appropriate stop location. ${ }^{[5]}$

The apex locator was developed in 1962 by Sunada ${ }^{[6]}$ and Stavrianos and al. ${ }^{[7]}$ Previous studies have shown that the latest electronic apex locator is reliable in determining the length of the endodontic work in $75 \%-96.5 \%$ of teeth with mature apexes.

In this study, the third-generation Morita Root ZX apex electronic locator was chosen due to its high reliability proven by numerous publications. The reported accuracy rate is $85 \%-95 \%$, even with electrolytes. ${ }^{[8-12]}$ The 1996 study by Shabahang et al. ${ }^{[13]}$ reports a reliability rate of up to $96.5 \%$.

The average DTIRA found in this study was 0.792 $\mathrm{mm} \pm 0.61$ (minimum: $0 \mathrm{~mm}$, maximum: $4.4 \mathrm{~mm}$ ). This maximum corresponded with a woman aged 51 years and for whom it was impossible to go beyond this measure. The average DTIRA found in this study was in the range of $0-2 \mathrm{~mm}$ and is consistent with the results that $\mathrm{Ng}$ et al. ${ }^{[14]}$ reported in 1990 for any endodontic treatment success. However, we obtained an average DTIRA of $>0.5$ $\mathrm{mm}$, which is the recommended constant in the radiological determination formula for the working length $=(\mathrm{LR} \pm$ $\mathrm{x})-0.5$, according to Kuttler's work. ${ }^{[1]}$

The data cross-checked by Kuttler ${ }^{[1]}$ suggested the apical constriction at $0.5-0.6 \mathrm{~mm}$ from the apical foramen on average. Several clinicians then suggested working at 0.5 $\mathrm{mm}$ from the apex.

The average found in this study was outside the range of success [1-2 mm] for endodontic treatment, as recommended by Gordon and Shandler's and Trope and Debelian's 2004 and 2005 studies. ${ }^{[15,16]}$ According to Trope and Debelian, ${ }^{[16]}$ the highest success rates following endodontic treatments are obtained from vital teeth with apical stops 1-2 mm from the radiographic apex. Due to root resorption, when the apical stop is beveled the shortest wall is considered. ${ }^{[5]}$ Our study focused only on live teeth because apical periodontitis is associated with resorption of alveolar bone, cementum, and intraductal dentin. The cementodentinal junction and apical constriction may be affected by resorption. ${ }^{[5]}$

The results herein also showed that the average DTIRA of patients aged 36-59 years is significantly higher than that of younger patients $(\mathrm{p}=0.001)$. This difference is due to the increase in cementum thickness with age and the removal of the cementodentinal junction and the apical constriction of the anatomical and radiographic apex. ${ }^{[1]}$

This study showed an apical constriction position at $0.5 \mathrm{~mm}$ of the radiographic apex in $21 \%$ of cases and in patients $<40$ years old. During his microscopic investigations on apexes, Kuttler ${ }^{[1]}$ found a relationship between the foramen and the vertex in $32 \%$ of younger subjects and $20 \%$ of elderly subjects. A more recent study by Ponce et al. ${ }^{[17]}$ on the optical microscopic assessment of the apical zone showed that the position of the apical foramen was at the anatomical apex in $27.7 \%$ of cases for patients $<42$ years old. However, the distance between the apical foramen and apical constriction was $0.5 \mathrm{~mm}$ in younger subjects according to Hülsmann and Schäffer. ${ }^{[18]}$ The results established by Kuttler ${ }^{[1]}$ in 1955 and by Ponce et al. ${ }^{[17]}$ in 2003 may apply to the apical constriction and thus be comparable to those of this study, which are lower.

In other words, Kuttler's, Harrán Ponce's, ${ }^{[17]}$ and our study showed that subtraction of $0.5 \mathrm{~mm}$ from the radiographic apexes recommended by several authors to determine the working length is possible only in $32 \%, 27.7 \%$, and $21 \%$ of cases, respectively.

This work showed that the electronic method currently remains the most reliable means of determination of working length. However, the joint use of radiography with a file and the apex locator reduces the risk of error.

\section{Conclusion}

Our data showed that there is substantial variability in the distance between the apical constriction determined by an apex locator and the radiographic apex on digital radiographs using the Kodak Dental Imaging Software ${ }^{\circledR}$ in this Moroccan population. The subtraction of $0.5 \mathrm{~mm}$ from the value as recommended by several authors is only possible in $21 \%$ of selected teeth. However, it is necessary to reproduce this study in other populations with other apex locators and conduct a histological cross-check to confirm these results.

Conflict of interestः None declared.

\section{References}

1. Kuttler Y. Microscopic investigation of root apexes. J Am Dent Assoc 1955;50:544-52. [CrossRef]

2. Simon S, Machtou P, Adams N, Tomson P, Lumley P. Apical limit and working length in endodontics. Dent Update 2009;36:146-53. [CrossRef]

3. Alothmani OS, Friedlander LT, Monteith BD, Chandler NP. Influence of clinical experience on the radiographic determination of endodontic working length. Int Endod J 2013;46:211-6. [CrossRef] 
4. Martins JN, Marques D, Mata A, Caramês J. Clinical efficacy of electronic apex locators: systematic review. J Endod 2014;40:759-77. [CrossRef]

5. Fennich M, Sakout M, Abdallaoui F. For a rational evaluation of working length in endodontics. Rev Odontomatol (Paris) 2012;41:232-43.

6. Sunada I. New method for measuring the length of the root canal. J Dental Res 1962;41:375-87. [CrossRef]

7. Stavrianos CH, Vladimirov ST, Vasiliadis L, Stavrianou I, Panayotov I, Pamporakis P. In vitro evaluation of the precision of four different electronic apex locators in determining the working length of teeth after removing root canal obturation materials. Res J Med Sci 2008;2:282-6.

8. Gohil UK, Parekh VV, Kinariwala N, Oza KM, Somani MC. Can active signals of cellphone interfere with electronic working length determination of a root canal in a dental clinic? An in vivo study. J Conserv Dent 2017;20:170-3.

9. Aydin U, Karataslioglu E, Aksoy F, Yildirim C. In vitro evaluation of Root ZX and Raypex 6 in teeth with different apical diameters. J Conserv Dent 2015;18:66-9.

10. Sriman N, Prabhakar V, Bhuvaneswaran JS, Subha N. Interference of apex locator, pulp tester and diathermy on pacemaker function. J Conserv Dent 2015;18:15-9. [CrossRef]

11. Santhosh L, Raiththa P, Aswathanarayana S, Panchajanya
S, Reddy JT, Susheela SR. Influence of root canal curvature on the accuracy of an electronic apex locator: An in vitro study. J Conserv Dent 2014;17:583-6. [CrossRef]

12. Koçak S, Koçak MM, Sağlam BC. Efficiency of 2 electronic apex locators on working length determination: A clinical study. J Conserv Dent 2013;16:229-32. [CrossRef]

13. Shabahang S, Goon WW, Gluskin AH. An in vivo evaluation of Root ZX electronic apex locator. J Endod 1996;22:616-8. [CrossRef]

14. Ng YL, Mann V, Gulabivala K. A prospective study of the factors affecting outcomes of nonsurgical root canal treatment: part 1: periapical health. Int Endod J 2011;44:583609. [CrossRef]

15. Gordon MP, Chandler NP. Electronic apex locators. Int Endod J 2004;37:425-37. [CrossRef]

16. Trope M, Debelian G. Endodontics Manual for the General Dentist. 1st ed. New Malden: Quintessence Pub Co; 2005. p. 69-74.

17. Ponce EH, Vilar Fernández JA. The cemento-dentino-canal junction, the apical foramen, and the apical constriction: evaluation by optical microscopy. J Endod 2003;29:214-9.

18. Hülsmann M, Schäffer E. Problems in endodontics: Etiology, Diagnosis and Treatment. New Malden: Quintessence publishing; 2009. p. 191-208. 